\title{
Identidade pela fotografia: construção e resgate da identidade na Comunidade Novo Aarão Reis
}

\author{
Identity through photography: identity construction and rescue of the \\ Community Novo Aarão Reis \\ Identidad a través de la fotografía: construcción de la identidad y el rescate \\ de la Comunidad Novo Aarão Reis \\ Laís de Paula Fiuza Costa ${ }^{1 *}$, Rodrigo Viana de Ávila²
}

Palavras-chave:

Saúde da Família

Fotografia

Identidade

Participação Comunitária

Promoção da Saúde

Keywords:

Family Health

Photography

Identity

Consumer Participation

Health Promotion

Palabras clave:

Salud de la Familia

Fotografía

Identidad

Participación Comunitaria

Promoción de la Salud

\section{Resumo}

Este artigo relata uma experiência inovadora de montagem expositiva itinerante de fotografias, que foi realizada no Centro de Saúde da Comunidade do Novo Aarão Reis, Município de Belo Horizonte, em Minas Gerais. Tem como objetivo apresentar uma forma de construção, resgate e manutenção da memória, história e identidade dos moradores da comunidade, na medida em que transforma a percepção dos moradores sobre si mesmos e sobre o mundo que os cerca. Ainda, expõe estes moradores a outros de outras localidades da imensa "aldeia global", fazendo surgir, sobre a coletividade, a percepção e a legitimidade de pertencer ao Novo Aarão Reis, não só de maneira física, mas também imaginativamente na perspectiva do simplesmente ser e pertencer.

\section{Abstract}

This article reports an innovative experience of mounting a traveling exhibition of photographs, which was held at the Community Health Center of Novo Aarão Reis, Municipality of Belo Horizonte, in Minas Gerais. It aims to present a form of construction, rescue, and maintenance of memory, history, and identity of the community residents, as it transforms the perception of residents about themselves and the world around them. Furthermore, it exposes these residents to others from elsewhere in our vast "global village", giving rise to the perception of the community and the legitimacy of belonging to the Novo Aarão Reis, not only in a physical way, but also imaginatively, "simply being and belonging".

\section{Resumen}

Este artículo relata una experiencia innovadora para crear una exposición itinerante de fotografías que se realizó en el Centro de Salud de La Comunidad de Novo Aarão Reis, Municipio de Belo Horizonte, en Minas Gerais. Su objetivo es presentar una forma de construcción, rescate y mantenimiento de la memoria, de la historia y de la identidad de los residentes de la comunidad en la que transforma la percepción de los residentes acerca de sí mismos y al mundo que les rodea. Además, expone ellos a otras comunidades de nuestra "aldea global", dando lugar a la percepción y la legitimidad de pertenecer a la comunidad de Novo Aarão Reis, no sólo de una manera física, sino también con imaginación de simplemente "ser con pertenencia"

Centro de Saúde Novo Aarão Reis; Prefeitura de Belo Horizonte. laisfiuza@gmail.com

${ }^{2}$ Historiador e fotógrafo, Brasil. avi.rod@gmail.com

${ }^{*}$ Autor correspondente.

Fonte de financiamento: Prefeitura Municipal de Belo Horizonte; Secretaria Municipal de Saúde.

Conflito de interesses: declararam não haver.

Recebido em: 20/06/2011

Aprovado em: 03/11/2011 


\section{Introdução}

\section{Comunidades carentes, identidade e pertencimento}

Quando pensa-se em comunidades carentes, talvez as primeiras ideias que surjam são: carência financeira, falta de estrutura física e urbanística, baixa escolaridade, falta de saneamento e outras mazelas que a sociedade de baixa renda sofre. Porém, existem outras carências que não podem ser desprezadas e que contribuem para o empobrecimento social de uma comunidade. São elas, as carências afetivas, artísticas e, por fim e talvez as mais importantes, as de memória e "identitária".

No mundo pós-moderno, a identidade se tornou diluída dentro de uma infinidade de propostas de ser, tornar e pertencer, as quais acabam trazendo angústias ao ser humano. É necessário pertencer e só é quando uma pessoa se dá conta do pertencimento e assume a participação na comunidade, é que valoriza a existência dela e luta por melhorias individuais e coletivas. Por exemplo, um fator grave dentro das comunidades empobrecidas é a falta da carteira de identidade e até mesmo certidão de nascimento de seus habitantes. Segundo Zygmunt Bauman, "[...] a ideia de 'ter uma identidade' não vai ocorrer às pessoas enquanto o 'pertencimento' continuar sendo o seu destino, uma condição sem alternativa', é preciso que o indivíduo perceba seu pertencimento e se identifique como parte de tal comunidade ${ }^{1}$.

Muitas vezes estes bairros periféricos surgem nas cidades após uma ocupação de terras ou mesmo apropriação de espaços públicos, feitas por migrantes de outras áreas mais carentes ou de cidades vizinhas. Ou seja, em muitos casos, estas pessoas estão extremamente à margem do que se exige para que se tenha a sensação de pertencimento. São indivíduos que estão longe de onde nasceram e vivem a precariedade e inconstância do lugar em que resolveram edificar suas casas. Neste sentido, "quando a identidade perde as âncoras sociais que a faziam parecer 'natural', predeterminada e inegociável, a 'identificação' se torna cada vez mais importante para os indivíduos que buscam desesperadamente um "nós"'.

A Comunidade Novo Aarão é um bairro localizado na região Norte do Município de Belo Horizonte, em Minas Gerais, no Brasil, que tem seu nome em referência ao bairro Aarão Reis - nome do urbanista responsável pela nova capital mineira. Surge de uma ocupação irregular, na qual, segundo relatos dos administradores e funcionários do Centro de Saúde, são em sua maioria migrantes do Norte de Minas, além dos antigos moradores do Povoado do Onça e trabalhadores das fazendas da região. A ocupação se consolidou na década de 1990 e, atualmente, o bairro conta com uma população de aproximadamente 10.000 pessoas. Seus habitantes são em grande parte famílias de baixa renda e com carências sociais e afetivas graves, sem desprezar ainda a violência cotidiana trazida pelo tráfico de drogas e outros. De acordo com Viviane Forrester, "estes são os primeiros a se considerar incompatíveis com uma sociedade da qual eles são os produtos mais naturais. São levados a se considerar indignos dela, e, sobretudo, responsáveis pela sua própria situação"2.

O sociólogo Zygmunt Bauman, em seu livro "Identidade", aponta para dois tipos de identidade: a de pertencimento e as de ideias e princípios.

"É comum afirmar que as 'comunidades' - às quais as identidades se referem como sendo as entidades que as definem - são de dois tipos. Existem comunidades de vida e de destino, cujos membros [...] 'vivem juntos em uma ligação absoluta', e outras que são 'fundidas unicamente por ideias ou por uma variedade de princípios"1.

Neste artigo, será tratado primordialmente do primeiro tipo de identidade abordado por Bauman, no qual, por pertencer ao bairro Novo Aarão Reis, em Belo Horizonte, as pessoas vivem juntas em uma ligação que forma a identidade dos moradores de determinado local.

Também deve-se estar atento para um dos cuidados ao se trabalhar identidade, pois, em diversas vezes na história da humanidade, a questão "identitária" foi utilizada como forma de segregar. E ainda é, sobretudo quando uma parcela da sociedade economicamente desfavorecida por um sistema excludente torna-se indesejável para outra parte, pois 'eles ainda não foram excluídos o bastante. Eles irritam'2.

O que pretende-se é exatamente o contrário da segregação. O intuito é agregar valor no momento em que o indivíduo da comunidade se sinta parte de um todo e, assim sendo, responsável por si mesmo e pela sociedade da qual faz parte. O objetivo é que, ao se sentir parte, o indivíduo consiga valorar a comunidade em que vive e, nesse sentido, perceba que pode construí-la com uma autoestima diferente da vivenciada quando tratado como um excluído. O morador do Novo Aarão Reis não faz parte tão somente do bairro em que vive.

É, também, parte importante e ativa da Zona Norte, da Cidade de Belo Horizonte, do Estado de Minas Gerais, do Brasil e da América do Sul, até que se enxergue como pertencente da imensa Aldeia Global em que vive, sendo beneficiado ou prejudicado por todas as engrenagens que movem tal sociedade e como membro ativo responsável direta e indiretamente pela forma como esse sistema age sobre si mesmo e sobre a comunidade a que pertence. 


\section{A fotografia e a identidade}

De acordo com Flavio Colker, em seu artigo "Retrato, Fotografia e Identidade", "o aspecto mais importante da fotografia é definir a identidade de coisas e pessoas" 3 . Concordando com essa máxima e pensando na sociedade do século 21 como aquela da imagem e do simulacro, entende-se que uma maneira eficaz de trazer à tona a identificação das pessoas da Comunidade Novo Aarão Reis com elas mesmas, com o bairro a que pertencem e com a sociedade da qual são membros ativos, poderia ser por meio da fotografia. Já no século 19 a fotografia era usada como forma de reforçar a identidade das famílias. Segundo Maria Eliza Linhares Borges, em seu livro "História e Fotografia": "Nas fotografias de família - fossem elas produzidas em estúdios ou não - o que interessava era a representação de papéis sociais. É com eles que se cria a identidade do grupo e se institui a memória de seus membros. Segundo Bourdieu, 'o álbum de família exprime a verdade da recordação social"' 4 .

Ainda segundo Borges, "Longe de ser um documento neutro, a fotografia cria novas formas de documentar a vida em sociedade. Mais que a palavra escrita, o desenho e a pintura, a pretensa objetividade da imagem fotográfica" ${ }^{4}$. A fotografia está longe de ser uma imagem inerte, é viva no sentido em que traz vida ao fotografado, dando-lhe voz não somente sobre a sua aparência retratada, bem como escancara sua vivência e pertencimento social. A memória é evocada, pois ao ser feita a fotografia, já não é mais presente, é o passado escrito em imagem que pode ser lembrado, comentado e estudado, não só no momento como no futuro. É o registro de um modo de vida, condição social, arquitetura e urbanismo, que trará luz e informação de geração à geração.

Além de ser um documento memorialístico, a fotografia também identifica e, como ferramenta de identificação, serve para ser trabalhada no sentido de ser usada ao reconhecimento de um lugar, de uma comunidade, de um Estado, seja o alvo da fotografia uma paisagem, uma obra arquitetônica ou o indivíduo de um lugar. "Após a Kodak, tudo e todos serão identificados com imagens [...]. Em pouco tempo, passamos a ser identificados através de imagem em passaportes, carteiras de identidade, jornais, filmes, televisão. Domínio absoluto da imagem fotográfica no cotidiano"3.

A ferramenta fotografia foi pensada neste projeto exatamente pelos sentidos colocados. Serviu para retratar a Comunidade Novo Aarão Reis e seus habitantes, inseridos em seu cotidiano, para serem posteriormente expostos em vários locais da comunidade, bem como para serem identificados por si e pelo outro como pertencentes àquela sociedade e por todas em torno dela. Por isso, a importância fundamental da exposição das fotografias ser itinerante, buscando levar 'para fora' os habitantes do Novo Aarão Reis expondo, assim, como um simulacro a sua existência em beleza estética, possível por meio do olhar do fotógrafo.

\section{Desenvolvimento}

Em 2010, durante o Internato de Atenção Integral à Saúde, no Centro de Saúde Novo Aarão Reis, Prefeitura de Belo Horizonte, dois acadêmicos, estudantes do $12^{\circ}$ período de medicina da Universidade José do Rosário Vellano, que participaram do grupo de palhaços Doutores Só Risos, foram convidados pela supervisora do referido Internato a desenvolverem um projeto com base na arte do palhaço, com fins de resgate psicossocial de crianças e adolescentes em situação de risco, moradores da Comunidade Novo Aarão Reis.

Durante a execução deste projeto, percebeu-se, pelos acadêmicos e seus professores, que a comunidade em que o trabalho era desenvolvido tinha além dos problemas comuns às áreas de risco, um grande vazio "identitário", no qual as pessoas se preocupavam pouco com a comunidade onde vivem e, assim sendo, não assumem sua individualidade enquanto participantes da sociedade. Essa percepção se deu pela vontade da comunidade, escola e centro de saúde em inserir o trabalho dos médicos em outros eventos e acontecimentos do bairro. No Novo Aarão Reis existem algumas manifestações culturais e artísticas que acabam ficando isoladas. Com o projeto do Centro de Saúde em desenvolvimento, ficou clara a necessidade de convergência de todas estas atividades para uma manifestação ainda maior e mais abrangente.

Ainda como parte do trabalho, foram convidados dois fotógrafos para o registro das atividades de "palhaçaria" que ocorriam no Centro de Saúde. Para além das atividades propostas, houve uma crescente demanda dos fotógrafos em registrar também o cotidiano do Centro de Saúde e do bairro Novo Aarão Reis.

Dentro desta lógica e aproveitando as fotografias geradas no Brincar de Viver, que é um projeto que trabalha por meio da linguagem lúdica do palhaço o resgate biopsicossocial das crianças em risco na comunidade, surgiu a ideia de se fazer uma exposição no centro de saúde com imagens da atividade dos acadêmicos, além de fotos do dia-a-dia do Centro de Saúde e da comunidade.

Os fotógrafos, por meio de reuniões com o grupo de médicos e de suas perspectivas e experiências, puderam ilustrar de maneira realística os trabalhos no Centro de Saúde e o cotidiano da comunidade, conforme pode ser apreciado nas Figuras 1 a 5 . 
Figura 1. Vozinha, por Rodrigo Ávila. Uma das mais antigas moradoras da Comunidade Novo Aarão Reis, reconhecida pela maioria dos moradores, é referência "identitária".

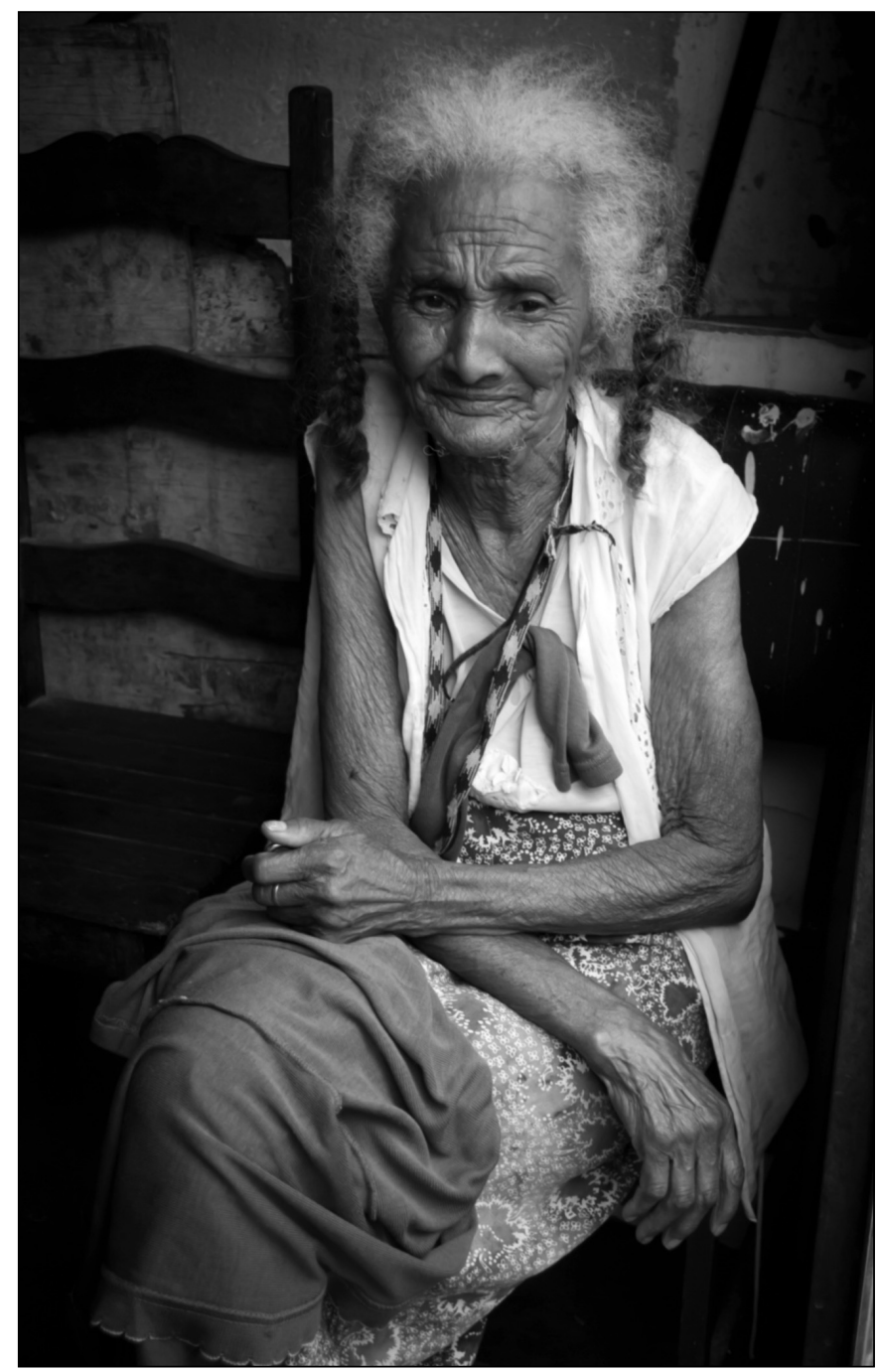

As saídas fotográficas foram marcadas sem um cronograma específico, sendo combinadas previamente entre os fotógrafos e os autores do projeto "Brincar de Viver". As fotografias foram feitas sem que o projeto de exposição fosse comunicado à comunidade, com o intuito de que não houvesse prévia preparação, já que a ideia central foi fotografar o cotidiano das pessoas de forma espontânea, pelo olhar do fotógrafo.

O olhar serve não só para expor - pela imagem e concepção artística - a identidade do indivíduo, como também para que este sujeito, ser social, objeto da fotografia se reconheça como pertencente a um todo não só como ser inserido, mas como um ser que atua e participa, sendo assim contemplado com o reconhecimento de si mesmo e da sociedade que o cerca com o pertencimento à Comunidade em questão.

A exposição, produto final do trabalho, teve como objetivo difundir, por meio de dois textos e uma mostra de
Figura 2. Escrava do crack, por Rodrigo Ávila. Jovem viciada em crack que se acorrentou para tentar conter a crise de abstinência.

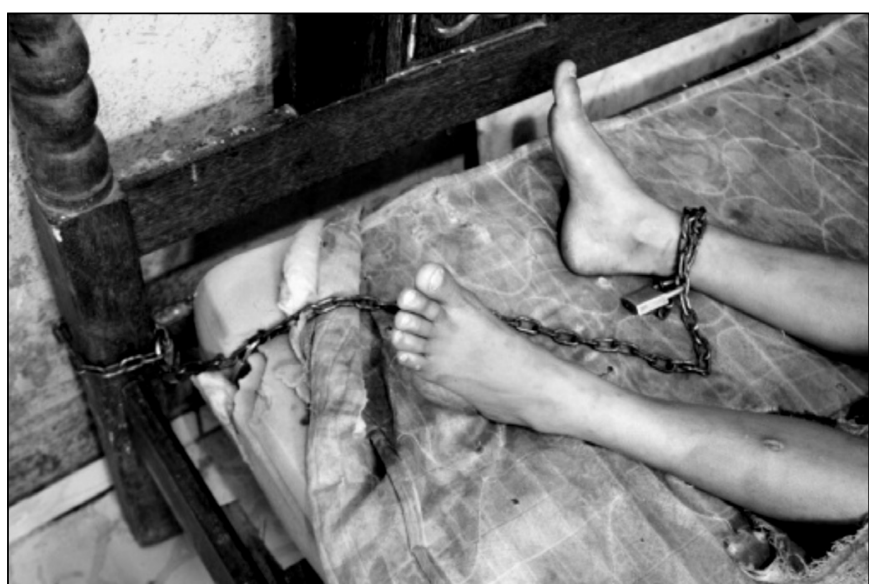

Figura 3. Amamos o Novo Aarão Reis, por Rodrigo Ávila. Criança carregando cartaz durante a "Palhaciata" (passeata de palhaços), promovida pelo "Brincar de Viver".

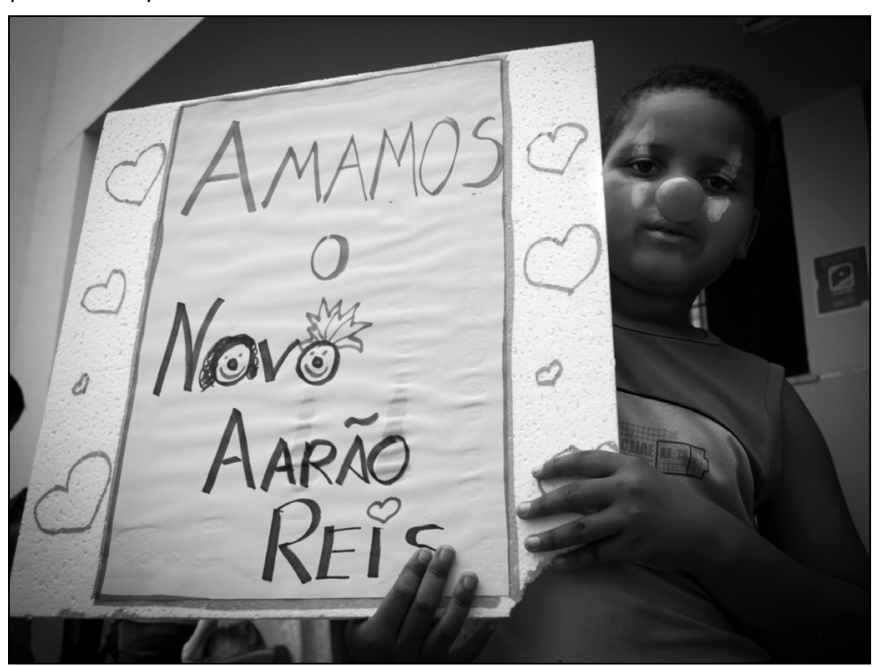

36 fotografias de personagens envolvidos, o trabalho que foi feito no Centro de Saúde e na comunidade, sendo a mesma itinerante e tendo a primeira mostra sido realizada no próprio Centro de Saúde Novo Aarão Reis. Posteriormente, a exposição seguirá para outros espaços: Universidade José do Rosário Vellano (campus de Belo Horizonte, Alfenas e outras cidades), Centros Culturais, Associação Médica Mineira, Congressos, Fóruns Municipais e onde mais possa ser requisitada e se fizer pertinente. As fotografias receberam autorização dos fotografados para fazerem parte do acervo, assim como para o uso no projeto em seus diversos formatos.

A perspectiva foi que a comunidade se sentisse pertencente e se identificasse pelas fotografias, buscando assim a valorização da imagem de cada um e o sentimento de pertencimento não só ao bairro, mas aos serviços prestados pela Prefeitura de Belo Horizonte em sua parceria com a Univer- 
Figura 4. Médica, palhaça e bailarina, por Rodrigo Ávila. Doutora Pisquila, antes acadêmica e atual médica no Centro de Saúde do Novo Aarão Reis, pertencente ao grupo Doutores Só Risos.

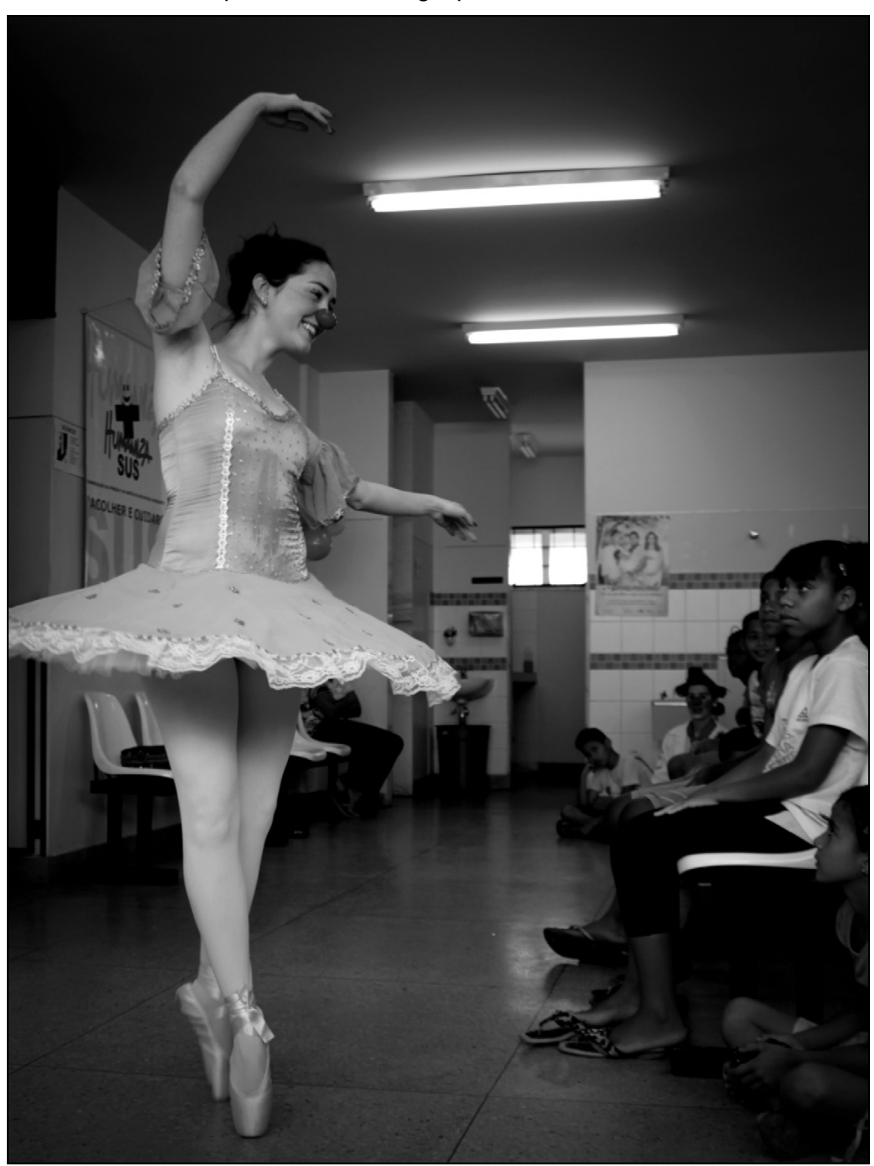

sidade José do Rosário Vellano. Ao se sentir contemplado pela Prefeitura que gere o bairro e perceber o interesse de instituições particulares na comunidade a que pertence, o indivíduo passa a se sentir parte de um todo que é observado e trabalhado pelo outro, podendo desta forma cobrar e se manifestar sempre que achar pertinente.

Buscou-se ainda a sensibilização de outros acadêmicos e mestres de que a medicina não é apenas uma ciência, mas, de fato, uma arte, um trabalho sociológico, além de mostrar que, para cada situação/comunidade/paciente, existe um tipo de linguagem que pode ser explorada como ferramenta tecnológica, no sentido de melhorar a vida das pessoas pensando no conceito holístico de saúde que envolve além da saúde física, a mental e o bem-estar social.

De acordo com Stuart Hall: "A questão da identidade está sendo extensamente discutida na teoria social. Em essência, o argumento é o seguinte: as velhas identidades, que por tanto tempo estabilizaram o mundo social, estão em declínio, fazendo surgir novas identidades e fragmentando o indivíduo moderno, até aqui visto como um sujeito unificado.
Figura 5. "Falar de mim é fácil, difícil é ser eu...", por Rodrigo Ávila. Carroceiro bastante conhecido na Comunidade pelo apelido de Zezão.

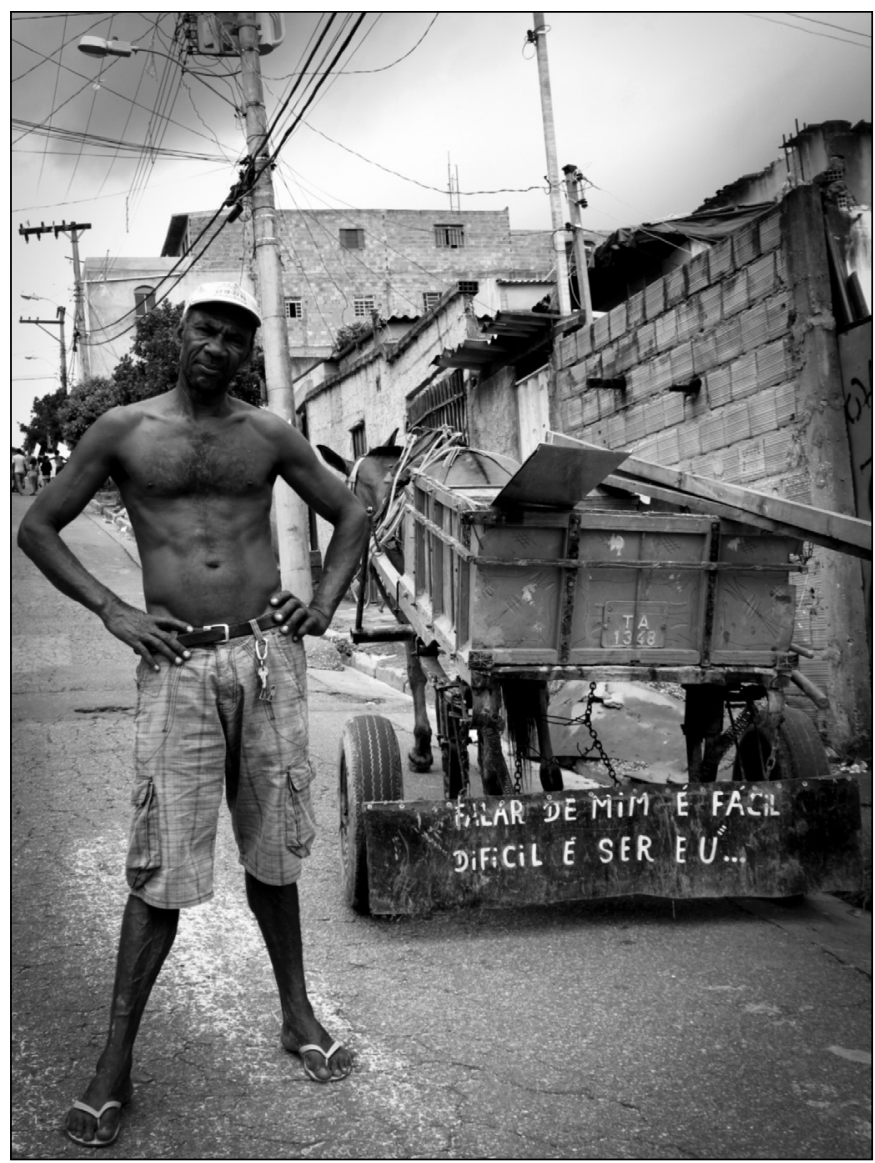

A assim chamada 'crise de identidade' é vista como parte de um processo mais amplo de mudança, que está deslocando as estruturas e processos centrais das sociedades modernas e abalando os quadros de referência que davam aos indivíduos uma ancoragem estável no mundo social"' .

Portanto, discutir e questionar essas mudanças, além de fazer parte delas, é importante para o médico e para aqueles que trabalham na saúde enquanto sujeitos importantes na formação social dos indivíduos.

Pretendeu-se, também, caso existam recursos e disponibilidade dos profissionais envolvidos, que seja feito um levantamento histórico do bairro Aarão Reis, em parceria com a Prefeitura de Belo Horizonte, por meio do Arquivo Público de Belo Horizonte, para ser posteriormente acrescentado a este trabalho. Existiu também a preocupação da maneira como esta pesquisa possa atingir os moradores do bairro, ajudando ainda mais no trabalho de valorização "identitária" da comunidade e dos indivíduos que pertencem a ela. Para tal, na abertura da próxima "itinerância", pretende-se realizar mais um documentário mostrando as 
reações do público. Também estão sendo recolhidos ao logo da exposição relatos sobre a reação das pessoas ao entrar em contato com as fotografias. Esses relatos estão sendo armazenados por meio digital e do livro de visitas da exposição. Esse material será agregado à exposição na medida em que for traçando seu caminho de "itinerância".

\section{Conclusões}

A prática de se reconhecer e ser reconhecido em uma fotografia traz à tona a identidade do sujeito perante sua comunidade. A partir do momento em que este é retratado, passa a fazer parte, é pertencente à comunidade, e aquele que não se encontra retratado também se reconhece como pertencente na medida em que questiona a sua não-exposição. Foram diversos os casos observados na abertura da exposição, nos quais os moradores do bairro questionavam a falta de uma fotografia sua na mostra, ou seja: se é uma exposição do Novo Aarão Reis, porque eu não estou inserido, já que faço parte? A sensação de pertencer é ainda maior, pois se torna defesa da identidade da qual se sente excluído.

Segundo a historiadora Lucília de Almeida Neves Delgado: "O homem é um ser permanentemente em busca de sim mesmo, de suas referências, de seus laços identificadores. A identidade, além de seus aspectos estritamente individuais, apresenta dimensão coletiva, que se refere à integração do homem como sujeito do processo de construção da História.
[...] a construção de identidades é também uma dinâmica através da qual a identificação das similitudes e a afirmação das diferenças situam o ser humano em relação aos grupos sociais que o cercam" ${ }^{\prime \prime}$.

Diante de tal afirmativa, não seria um despropósito pensar neste trabalho como forma de construção, resgate e manutenção da memória, história e identidade dos moradores do Novo Aarão Reis à medida que transforma a percepção dos moradores desta localidade sobre si mesmos e sobre o mundo que os cerca. Mais ainda, expõe estes moradores a outros de outras localidades da imensa Aldeia Global, fazendo surgir sobre a coletividade a percepção e a legitimidade de pertencer ao Novo Aarão Reis, não só seus habitantes de maneira física, mas também aqueles que se deslocam, mesmo que imaginativamente para junto de pessoas tão nobres de simplesmente ser e pertencer.

\section{Referências}

1. Bauman Z. Identidade: Entrevista a Benedetto Vecchi. Rio de Janeiro: Zahar; 2005.

2. Forrester V. O Horror Econômico. São Paulo: Unesp; 1997.

3. Colker F. Retrato, Fotografia e Identidade. 2009. [Internet]. [acesso em 2011 Abr 20]. Disponível em: http://www.olhave.com.br/blog/wpcontent/uploads/2009/12/Retrato-Fotografia-e-Identidade.pdf.

4. Borges MEL. História e fotografia. Belo Horizonte: Autentica; 2003.

5. Hall S. A identidade cultural na pós-modernidade. Rio de Janeiro: DP\&A; 2006.

6. Delgado LAN. História Oral, Memória, Tempo, Identidade. Belo Horizonte: Autentica; 2006. 